\title{
ALTERAÇÕES DE TEMPORALIDADES NO ESPAÇO URBANO ATRAVÉS DA CASA DO FLAMENGO
}

\author{
José Luiz Kinceler ${ }^{1}$, Marcelo Wasem²
}

Palavras-chave: espaço urbano, jogo, rito, acontecimento.

Resumo: O presente artigo realiza uma análise teórica sobre a casa de seu Machado, na cidade de Florianópolis, e a transformação plástica que este vem realizando nela. Para a reflexão teórica foram utilizados as noções de jogo e rito em Johan Huizinga e Giorgio Agamben, e relacionando com o conceito de acontecimento, de Gilles Deleuze, a fim de traçar paralelos com o campo da arte.

\section{Introdução}

O presente artigo trata da questão sobre a influência que diversos agentes de fora do campo da arte vêm atuando neste, e conseqüentemente ampliando suas especificidades e suas formas de efetivação. Alguns destes procedimentos e outros apontamentos serão abordados através de uma análise teórica sobre a casa de seu Machado, um morador no bairro da Caeira do Saco dos Limões, na cidade de Florianópolis (SC), e a transformação plástica que este vem realizando nela.

Seu Machado é um senhor solteiro, sem filhos, flamenguista, passista da Escola de Samba Consulado. Através da transformação permanente da sua casa, construiu um diálogo muito particular com sua comunidade. Seu Machado também promove uma alteração na imagem do espaço público em conjunto com os outros moradores da comunidade, uma vez que suas ações e rotinas contribuem para que novas relações interpessoais aconteçam. Partindo do muro até as paredes da casa, objetos das mais diversas origens são re-significados, fundamentada em experiências relacionais que seu Machado, seu proprietário, estabelece com os moradores e não-moradores da citada comunidade.

Neste artigo, primeiramente serão descritas as principais características da comunidade, da casa e seu morador para, em seguida, realizar reflexões teóricas. Serão aprofundadas as noções de jogo e rito em Johan Huizinga e Giorgio Agamben, relacionando também com o conceito de acontecimento, de Gilles Deleuze, podendo ao fim colocar alguns apontamentos em consonância ao campo da arte.

\footnotetext{
${ }^{1}$ Professor Doutor no Departamento de Artes Plásticas da Universidade Estadual de Santa Catarina (UDESC).

${ }^{2}$ Mestrando no Programa de Pós-Graduação em Artes Visuais (PPGAV), linha de Processos Artísticos Contemporâneos, na Universidade Estadual de Santa Catarina (UDESC).
} 


\section{A Caeira e a casa do Flamengo}

A Caieira do Saco dos Limões é um bairro localizado em um vale cercado de morros, na baía sul da ilha de Santa Catarina. É uma das diversas comunidades antigas da cidade de Florianópolis e possui um ambiente social familiar mais próximo a uma cidade de interior. As casas geralmente unifamiliares apresentam linhas retas predominantes e sempre possuem os limites dos terrenos bem definidos. Uma casa porém quebra esta linearidade: a casa do seu Machado, também conhecida carinhosamente pela comunidade como a casa do Flamengo.

De longe, ela parece estar recoberta somente com as cores vermelha e preta, as mesmas do time de futebol Flamengo. Entrando pela rua estreita, novos objetos são revelados dentro do perímetro da propriedade, desde o muro, passando pelo quintal e chegando até o limite externo da casa. No muro uma profusão de objetos de origens diversas estão permanentemente instalados.

O critério que seu Machado utiliza para selecionar estes itens está relacionado com sua rotina de realizar caminhadas diárias. Nestes percursos ele encontra objetos que simplesmente estão pela estrada ou que foram jogados no lixo, diversos materiais de construção que sobram de obras, além de não negar a possibilidade de comprar outros artigos que por ventura ele se depare no caminho. Ao longo do tempo, seu Machado desenvolveu um olhar particular para selecionar objetos, pensando tanto no resultado estético quanto na durabilidade destes diante das condições de exposição.

Mas ele não é somente o único agente transformador. Com o passar do tempo os vizinhos e outras pessoas que passavam pela casa começaram a participar da transformação da casa, doando objetos que, segundo estes, combinavam com ela. Seu Machado afirma que aceita todos os objetos que lhe dão, pois valoriza além do objeto em si a atitude da doação, que reflete a afetividade das outras pessoas por ele. Neste sentido, também é criado um vínculo sentimental por parte de quem participa, uma vez que este vê sua contribuição esta composição.

A casa possui outras temáticas relacionadas às preferências do seu morador. Imagens da religião católica são encontradas em diversos pontos da moradia, e no quintal está construída uma edificação importante, não só para seu Machado como para a toda comunidade: a 'grutinha' para Nossa Senhora Aparecida. A novena para a santa é um evento realizado todo ano no dia doze de outubro, onde todos os moradores são convidados, se reunindo no altar construído no quintal da casa. Na frente deste, três bancos retangulares de cimento e sem encosto foram projetados para receber outras pessoas neste evento.

Outra importante atividade que seu Machado desenvolve no bairro é a festa de Natal para as crianças da comunidade. Durante o ano ele recolhe latas de alumínio cuja finalidade é serem vendidas para que sejam comprados doces e balas. Seu Machado se veste de Papai Noel e no dia da festa, ele percorre toda a comunidade de carro e entrega um kit com doces, balões e

DAPesquisa, Florianópolis, v.2, n.4, p. 197-203, 2007. 
pirulitos na quadra esportiva do bairro. Todos o chamam de 'Papai Noel da Caeira', embora quando questionado pelas crianças seu Machado nunca admite esta outra identidade.

Como se pode notar, sua atuação no bairro e interação com todos os seus habitantes são de considerável relevância para o contexto. Todo este conjunto de relações entre público e privado, o desejo pessoal e comunitário, e as permanentes alterações que a casa e seu morador provocam foram os motivadores para que fosse realizada a atual investigação.

\section{Reflexões teóricas}

Para realizar as reflexões teóricas, primeiramente, a casa de seu Machado será relacionada com a noção de jogo, identificando também os procedimentos com o conceito de acontecimento demarcado por Gilles Deleuze.

Johan Huizinga (1938) foi um dos primeiros teóricos a atribuir ao jogo importância fundamental para a formação da sociedade tal como a conhecemos. No primeiro capítulo de seu livro "Homo Ludens", o autor procura elencar as principais características que podem definir tal atividade. A primeira delas é seu caráter não-obrigatório - um exercício de liberdade. Para que seus participantes realmente integrem o jogo, estes devem usufruir do livre arbítrio para que este outro ambiente com regras próprias seja criado e jogado. A segunda característica se refere a este espaço que se instaura dentro da vida habitual, mas que não pertence a ela, "pelo contrário, trata-se de uma evasão da vida "real" para uma esfera temporária de atividade com orientação própria" (1990, p.11). Duas outras especificidades do jogo seriam a não-seriedade, enquanto uma atividade mais associada ao aspecto do divertimento, e seu caráter autônomo, sendo a sua finalidade a própria realização.

Huizinga ainda se refere a uma delimitação no tempo, enquanto uma experiência que possui uma duração predestinado a um fim, além de poder permanecer desde uma memória individual até se fixar enquanto fenômeno cultural. No espaço, pensa que o jogo necessita de uma área previamente demarcada para seu desenrolar e não vê diferenças entre os ambientes destinados ao jogo e ao culto, ou ao 'sagrado', uma vez que ambos possuem regras internas, instauradas em universos temporários dentro do "mundo habitual" (id., p.13).

Este tema é retomado pelo filósofo italiano Giorgio Agamben. No texto "O País dos Brinquedos" (2005) o autor apresenta outros procedimentos na qual acredita ser pertinente para explicar a relação das sociedades com o jogo e o rito e que modificam a percepção do tempo. De acordo com o lingüista Benveniste (apud Agamben, 2005) o jogo surge da esfera do sagrado. As cartas de baralho, o pião, o tabuleiro de xadrez e outros jogos têm sua origem como instrumentos divinatórios que, uma vez desconectados de sua função dentro do rito, acabam subvertendo seu antigo domínio e se consolidando enquanto 'sagrado às avessas'. Esta desconexão é realizada, quando os elementos fundamentais da operação sacra são desvinculados 
do contexto sagrado, transformando assim o mito em palavras e o rito em ações. Significantes que perdem seus significados, mas que irão adquirir outros.

Para Agamben, o jogo e o brinquedo possuem esta mesma característica de resignificação, embora este último seja apontado pelo autor como um objeto especial onde "podemos captar a temporalidade da história no seu puro valor diferencial e qualitativo" (id., p. 86). O brinquedo pertence tanto à sincronia, pela capacidade de resgatar o passado em um momento presente e unir estas duas temporalidades, quanto à diacronia ${ }^{3}$ quando este é utilizado por alguém que brinca durante um período de tempo, materializando assim um índice da temporalidade humana e assumindo-se enquanto um objeto que reside em um tempo suspenso ${ }^{4}$.

Continuando a diferenciação entre rito e jogo sob a perspectiva de investigar como cada operação se relaciona com o tempo, Agamben atribui ao primeiro a função de construir conexões entre passado e presente, "anulando o intervalo que os separa e reabsorvendo todos os eventos em uma estrutura sincrônica" (id., p. 90). Por outro lado, o jogo rompe com tais estruturas, transformando-as em eventos diacrônicos, que se estendem pelo tempo de acordo com o instante no momento de vivência. Com o rito é posto uma ordem no caos do mundo, estabelecendo os dias de trabalho e de descanso no período da semana ou fixando as datas para comemorações dentro do calendário em um movimento cíclico. Com o jogo é instaurado um fragmento de caos à ordem, tornando a estrutura rígida em um evento maleável e rizomático, como em uma partida de xadrez na qual por um determinado tempo somente 'vale' as regras relativas a este jogo. Anteriormente esta última característica foi atribuída ao rito, e não ao jogo. No entanto o que Agamben (id., p.90) aprofunda sobre a questão é que

rito e jogo apresentam-se principalmente como duas tendências operantes em toda a sociedade, que não conseguem, porém, eliminarse reciprocamente e que, mesmo prevalecendo uma sobre a outra em proporções diversas, deixam sempre substituir um resíduo diferencial entre diacronia e sincronia.

Este resíduo diferencial entre as duas formas de experimentação do tempo é o que funda a noção de história ou tempo humano. Ela é "o resultado das relações entre significantes diacrônicos e sincrônicos que rito e jogo produzem incessantemente" (id., p. 93). O rito, então, está sempre em busca de transformar eventos diacrônicos em estruturas sincrônicas, enquanto o jogo se configura em trazer sincronia para as estruturas diacrônicas ${ }^{5}$.

Traçando relações entre os apontamentos teóricos de Agamben e a casa do seu Machado pode-se notar que ela provoca alternações nas noções de temporalidade que envolve a casa,

\footnotetext{
${ }^{3}$ Por diacronia entende-se o conjunto de fatos que se estende ao longo do tempo (do grego diá 'através de' e khrónos 'tempo'), enquanto sincronia se refere à capacidade de simultaneidade dos eventos (do advérbio prepositivo grego sún 'juntamente; ao mesmo tempo').

${ }^{4}$ Assim como a operação que o colecionador realiza com seu objeto colecionado: retira-o da diacronia e também o furta da sincronia, tornando este irresoluto na história: nunca caberá ao presente, tão pouco pertence ao passado.

${ }^{5}$ Lévy-Strauss (apud Agamben, 2005) reformula a categorização entre sociedades com história cumulativa e as 'sem história', associando às primeiras aquelas onde o jogo tende a expandir-se em relação ao rito, denominando sociedades 'quentes', e às últimas onde o rito prevalece diante do jogo, de sociedades 'frias'.
}

DAPesquisa, Florianópolis, v.2, n.4, p. 197-203, 2007. 
qualificando também um modo específico de procedimentos relacionais que o morador e as outras pessoas constroem.

O que concerne sobre a questão do tempo pode-se afirmar que, por estar em constante transformação, a casa persiste no tempo como algo que não consegue ser absorvido pelo passado, e simultaneamente engloba diversas temporalidades através dos múltiplos objetos que vão sendo agregados a casa. Ela se assemelha a especificidade que Agamben atribui ao brinquedo, de estar suspenso no tempo, ao agrupar objetos de diversas épocas em uma composição sincrônica (todos ali, ao mesmo tempo) e também se estabelece na diacronia, por se constituir enquanto uma experiência que possui duração. Tanto para aqueles que interagem com a casa em determinados momentos quanto para seu Machado, que a vivencia diariamente. É desta forma que a casa desliza entre estas duas conceituações de tempo, não se fixando em nenhum dos dois pontos, mas realizando este permanente movimento de um modo lúdico e completamente participativo.

Seu caráter de construir conexões entre objetos de origens diversas e anular o intervalo entre eles nos remete ao mecanismo associado por Agamben ao rito. Esta relação pode ser ainda observada em, pelo menos, três outras situações que identificam seu Machado e, conseqüentemente, sua casa: doze de outubro (comemoração do dia de Nossa Senhora Aparecida), o natal e o carnaval, já citados acima.

Tais eventos são fundamentados dentro da lógica do rito, uma vez que possuem data certa para acontecerem e uma estrutura culturalmente construída a ser seguida. Mesmo assim, o lugar onde estas experiências são posteriormente relatadas (a casa) e sua configuração predisposta ao diálogo com as outras pessoas se apresentam como táticas com características semelhantes ao jogo (tendo como base as considerações de Agamben), ou seja, transformando estruturas rígidas em experiências vivas e compartilháveis. Eventos abertos à interação, seja no ato (como no caso da novena ou da festa de natal) ou a posteriori quando inseridas na composição da casa.

Até aqui já foi dissertado sobre as possibilidades de como estes tipos de relações acontecem. No entanto, o que une a casa e suas interseções com o debate acerca das especificidades da arte é um tipo de evento chamado de 'acontecimento', proposto por Gilles Deleuze (1989).

Este autor retoma a idéia dos estóicos de conceituar o tempo em duas expressões distintas: um representado por Cronos e outra por Aion. Enquanto para Cronos só há o presente, que engloba passado e futuro em uma estrutura sincrônica (pode-se associar ao conceito de rito de Agamben) em instantes que se sucedem incessantemente, Aion seria a fragmentação ilimitada do que passou e do que está por vir em um presente onde são desenvolvidos os eventos com duração (pode-se associar ao conceito de jogo de Agamben). À temporalidade de Cronos pertencem os corpos e as coisas, e é nele que as causas se originam. Ao passo que Aion diz 
respeito ao incorpóreo, o que não possui matéria, efeitos dos encontros entre corpos. O acontecimento se situa na intersecção dos dois registros temporais pelo fato de provocar alterações na materialidade das coisas e, ao mesmo tempo, continuar sendo sempre o que acabou de passar ou o que está por devir, nunca se efetivando no presente puro. Este caráter ambíguo do acontecimento pode ser associado à casa do seu Machado, uma vez que ela se apresenta como um resultado material do fator tempo, embora nunca esteja completamente finalizado, permanecendo em uma situação de constante processo.

Deleuze (1989) ainda aponta uma dupla estrutura relativa ao acontecimento. Todo o ato de efetuação de um acontecimento possui em potencial uma ação de contra-efetuação, uma possibilidade de surpreender a própria realização da ação no momento em que esta se realiza. Isso porque uma parte do acontecimento permanece sempre em devir, mesmo quando este está 'acontecendo', co-existem ali todas as outras formas de proceder que não estão em execução. A contra-efetuação, desta forma, se apresenta como um elemento inesperado presente em qualquer circunstância, não atribuindo ao acaso tal procedimento, mas sim como uma possibilidade ilimitada de ação que pode ser efetuada a qualquer instante.

Neste sentido, a casa e as ações de seu Machado, mesmo que pautadas dentro das características de um simples morador de uma comunidade com suas rotinas, oportuniza que estas diversas operações possam acontecer, em efetuações e contra-efetuações com táticas extremamente relacionais.

\section{Considerações finais}

Este caráter múltiplo do acontecimento que a casa carrega (reafirmado pelo seu morador) é, para esta pesquisa, de suma importância para pensar as experiências relacionadas ao campo das artes.

Atualmente não mais importa somente o resultado material de um trabalho de arte, enquanto um produto realizado pelo artista, mas sim o nível de interação que o espectador possui diante de tal experiência. Esta participação pode se dar no âmbito subjetivo de quem experiencia, mas tal vivência tende a ganhar outra amplitude quando artista e espectador entram em contato, podendo gerar produtos materiais ou, simplesmente, experiências de convívio e aprendizagem mútua. É neste sentido que os processos de construção da casa são potentes. A casa não se configura somente pelo resultado do desejo e das ações de seu morador, mas de um somatório de experiências que se dão na e através da casa.

\section{Referências Bibliográficas}


AGAMBEN, Giorgio. Infância e história: destruição da experiência e origem da história. Belo Horizonte: Editora UFMG, 2005.

HUIZINGA, Johan. Homo ludens: o jogo como elemento da cultura. Trad. João Paulo Monteiro. 2a edição. Ed. Perspectiva: São Paulo. 1990.

DELEUZE, Gilles. Lógica del sentido. Trad. Miguel Morey. Disponível em: http://www.heterotopiaz.boom.ru/00/007.pdf Acessado em 5 de maio de 2007. (1989) 